\title{
Synthesis and characterization of protocatechuic acid-loaded gadolinium-layered double hydroxide and gold nanocomposite for theranostic application
}

\author{
Muhammad Sani Usman ${ }^{1} \cdot$ Mohd Zobir Hussein $^{1}$ - Aminu Umar Kura ${ }^{5}$ - Sharida Fakurazi ${ }^{2}$ Mas Jaffri Masarudin ${ }^{3}$. \\ Fathinul Fikri Ahmad Saad ${ }^{4}$
}

Received: 5 January 2018 / Accepted: 26 March 2018 / Published online: 30 March 2018

(c) The Author(s) 2018

\begin{abstract}
A theranostic nanocomposite was developed using anticancer agent, protocatechuic acid (PA) and magnetic resonance imaging (MRI) contrast agent gadolinium nitrate (Gd) for simultaneous delivery using layered double hydroxide (LDH) as the delivery agent. Gold nanoparticles (AuNPs) were adsorbed on the surface of the LDH, which served as a complementary contrast agent. Based on the concept of supramolecular chemistry (SPC) and multimodal delivery system (MDS), the PA and Gd guests were first intercalated into the LDH host and subsequently AuNPs were surface adsorbed as the third guest. The nanohybrid developed was named MAPGAu. The MAPGAu was exposed to various characterizations at different stages of synthesis, starting with XRD analysis, which was used to confirm the intercalation episode and surface adsorption of the guest molecules. Consequently, FESEM, Hi-TEM, XRD, ICP-OES, CHNS, FTIR and UV-Vis analyses were done on the nanohybrids. The result of XRD analysis indicated successful intercalation of the Gd and PA as well the adsorption of AuNPs. The UV-Vis release study showed $90 \%$ of the intercalated drug was released at $\mathrm{pH} 4.8$, which is the $\mathrm{pH}$ of the cancer cells. The FESEM and TEM micrographs obtained equally confirmed the formation of MAGPAu nanocomposite, with AuNPs conspicuously deposited on the LDH surface. The cytotoxicity study of the nanohybrid also showed insignificant toxicity to normal cell lines and significant toxicity to cancer cell lines. The developed MAGPAu nanocomposite has shown prospects for future theranostic cancer treatment.
\end{abstract}

Keywords Nanolayers · Layered double hydroxides · Protocatechuic acid · Gadolinium · Gold nanoparticles · Theranostic delivery systems

\section{Introduction}

Nanostructured materials/nanomaterials research is fast becoming a leading field of interest in material science. This is due to the superior properties associated with these materials compared to their counterparts outside the nanorange.

Muhammad Sani Usman

muhusma@gmail.com

$\triangle$ Mohd Zobir Hussein

mzobir@upm.edu.my

1 Materials Synthesis and Characterization Laboratory, Institute of Advanced Technology (ITMA), Universiti Putra Malaysia, 43400 Serdang, Selangor, Malaysia

2 Department of Human Anatomy, Faculty of Medicine and Health Sciences, Universiti Putra Malaysia,

43400 Serdang, Selangor, Malaysia
The properties include, electrical, catalytic, magnetic, optical, and biological properties (Usman et al. 2013). As a result, nanomaterials demonstrate wide range of applications, particularly in biomedicine. As of yet, there is no unified definition of nanomaterials, however, the most recognized definition of nanoparticles universally 'is materials

3 Department of Cell and Molecular Biology, Faculty of Biotechnology and Biomolecular Sciences, Universiti Putra Malaysia, 43400 Serdang, Selangor, Malaysia

4 Centre for Diagnostic and Nuclear Imaging, Faculty of Medicine and Health Sciences, Universiti Putra Malaysia, 43400 Serdang, Selangor, Malaysia

5 Department of Pharmacology, Faculty of Basic Health Sciences, Bauchi State University, PMB 65, Gadau, Bauchi, Nigeria 
with a size range of 1-100 nm' (Krishnamoorthy et al. 2012; Mirza and Siddiqui 2014; Usman et al. 2013). Nonetheless, the definition of a nanomaterial according to the International Organization for Standardization (ISO) is "a material with any external dimensions in the nanoscale or having internal structure or surface structure in the nanoscale" (National Institute for Public Health and the Environment, Ministry of Health, Welfare and Support 2012).

Layered double hydroxides (LDHs) are nanostructured materials that belong to the class of inorganic 2D nanolayers or nanomaterials, and have a general formula of $\left[\mathrm{M}_{1-x}^{2+}\right.$ $\left.\mathrm{M}_{x}^{3+} \mathrm{OH}_{2}\right]\left(\mathrm{A}^{n-1}\right) x / n$, which comprise of divalent and trivalent metal cations, and interlayer exchangeable anions, represented by $\mathrm{M}^{2+}$ and $\mathrm{M}^{3+}$, and $\left(\mathrm{A}^{n-1}\right) x / n$, respectively (Nityashree and Menezes 2013). Water molecules are also found within the interlayers. The LDHs structured system supports the simultaneous intercalation and surface adsorption of external molecules through different forms of molecular interactions, mainly hydrogen bonding and electrostatic interactions (Usman et al. 2017a, b).

Cancer related diseases have being steadily on the rise globally with an annual increase (WHO cancer 2017; Yuan et al. 2017). Nano-based carriers have been used in the delivery of various anticancer agents (Bullo and Hussein 2015), because of their benefits of passive accumulation in the cancer cells via enhanced permeability and retention effect (EPR) (Duc et al. 2014). The effect also favors its use in theranostic delivery system (TDS). A TDS is a nanodelivery system that consists of nanodelivery agents, such as LDHs that are loaded with at least one diagnostic agent and a therapeutic agent (Sheng et al. 2013) for the purpose of simultaneous delivery of both to a desired target. The newly yet to be established system, could offer a more comprehensive cancer treatment particularly in cancer chemotherapy, which could be used both for cancer treatment and diagnosis.

Magnetic resonance imaging (MRI) is a diagnostic technique commonly used in cancer diagnosis. The non-invasive and decades old imaging technique has the ability to penetrate body tissues at a high imaging resolution (Tang et al. 2013). One of the drawbacks of this technique is its low sensitivity, which necessitates the use of diagnostic contrast agents. The only FDA approved MRI contrast agents are gadolinium-based contrasts, which mostly appear in chelates forms. The role of the contrasts agents is basically to shorten the relaxation times of the spin-lattice relaxation and the spin-spin relaxation signal, designated as T1 and T2, respectively (Usman et al. 2017a, b; Xu et al. 2012). Each signal produces different contrast in the tissues. The MRI contrast agents together with any anticancer agent loaded on a nanocarrier makes up a theranostic system. Protocatechuic acid (PA) was used as the anticancer agent in this work, which is a natural product found in numerous plants of high medicinal repute, such as Hypericum perforatum $L$,
Hibiscus sabdariffa L. and Ginkgo biloba L. The drug has been reported to have certain pharmacological properties, including anti-antimicrobial (Liu et al. 2008), anti-inflammatory (Liu et al. 2002) cardio-protective and anti-genotoxic, (Anter et al. 2011) anti-mutagenic, (Stagos et al. 2006) and most importantly anticancer (Yin et al., 2009) and antitumor (Nakamura et al. 2000). So far, only two articles have reported the use of LDH in the delivery of protocatechuic acid for anticancer efficacy studies and none for theranostic research. The works were reported by our research group (Barahuie et al. 2012, 2013), where the protocatechuic acid was intercalated into the LDH interlayer gallery using different loading methods (direct and ion-exchange). The developed drug delivery systems in both cases were observed to have cytotoxic effects against cancer cell lines, although the ion-exchange method-based nanocomposite showed higher drug delivery. Nevertheless, no article has reported the use of LDH/PA in theranostic delivery system. We believe this work is the first to use LDH and PA in a theranostic setting.

Here in, we intercalated Gd and then the PA, which resulted in the MAGPA nanocomposite; subsequently AuNPs were adsorbed at the surface. Theranostic delivery studies were followed. The final nanocomposite (MAPGAu) was used for the MRI contrast testing. In general, the use of LDH in theranostics is rather limited as highlighted in a recent review by Usman et al. 2017a, b considering the potential it has in this new area of nanoscience or in particular, nanomedicine.

\section{Results and discussion}

\section{X-ray diffraction}

Powder X-ray diffraction (PXRD) diffractograms of the pure starting material and the nanohybrids formed at various stages is displayed in Fig. 1a-d, which depicts all the diffraction patterns, where A represents pure protocatechuic acid and $\mathrm{B} \mathrm{Gd}\left(\mathrm{NO}_{3}\right)_{3}$. The diffractions shown in Fig. 1c are from the pure LDH phase, which have major reflections at $2^{\circ} \theta$ positions 10.0 and 20.0 with basal spacing of 7.7 and $4.2 \AA$, respectively (Usman et al. 2017a, b). The LDH was first synthesized as the nanocarrier, which was used to intercalate the drug and the $\mathrm{Gd}\left(\mathrm{NO}_{3}\right)_{3}$ into the interlayers of the LDH (MAPGA) as shown in Fig. 1d, the positions of the reflections appear to have shifted to the lower position of $2^{\circ} \theta(8.5)$, which results in an increase in the basal spacing to $10.5 \AA$. This is also suggestive of successful intercalation of the drug (Barahuie et al. 2014) as well as the $\mathrm{Gd}\left(\mathrm{NO}_{3}\right)_{3}$ within the interlayer gallery of the LDH. The diffractogram in Fig. 1e portrays completely different diffraction patterns, due to surface coating by AuNPs, since the final stage of the synthesis is the growing of AuNPs on the 


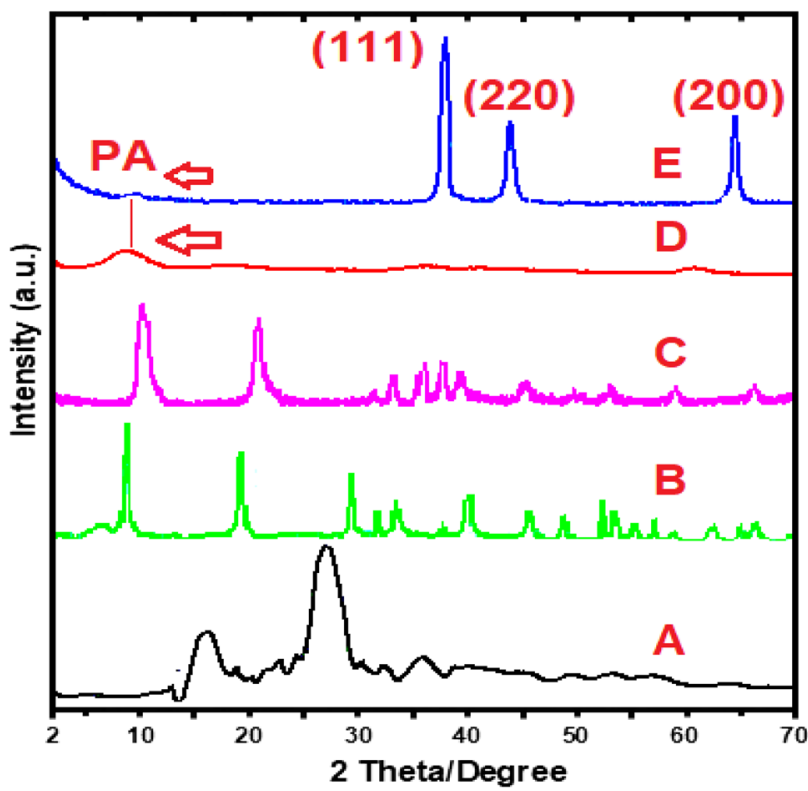

Fig. 1 X-ray diffractograms of a pure protocatechuic acid, b $\mathrm{Gd}\left(\mathrm{NO}_{3}\right)_{3}$, c $\mathrm{Mg} / \mathrm{Al}-\mathrm{LDH}$, d drug-intercalated $\mathrm{Mg} / \mathrm{Al}-\mathrm{LDH}-\mathrm{Gd}$ nanocomposite (MAPGA), e drug-intercalated Mg/Al-LDH-Gd coated with AuNPs (MAPGAu)

LDH-Gd drug nanocomposite (MAPGAu). As can be seen, the $2^{\circ} \theta$ peaks at $39.2,44.5$ and 64.9 , which match with 111 , 220 and 200 reflection, respectively, are of the FCC of pure gold nanoparticles as revealed by the JCPDS reference data (98-006-0833) of the sample. This is an affirmation of coating of the MAPGA surface with the synthesized AuNPs and the eventual formation of TDS (Uppal et al. 2013).

\section{Spatial orientation of the intercalated protocatechuic acid in the layered double hydroxide interlayer}

Figure 2 illustrates a typical theranostic delivery setting of $\mathrm{LDH}$ as the nanocarrier. The figure also shows the schematic of a three-dimensional (3D) molecular size of protocatechuic acid constructed with Chemoffice software 2008 (Cambridge, MA). As obtained from the software estimates, the $x$-, $y$ - and $z$-axes of the pure protocatechuic acid were observed to be $9.0,6.8$, and $2.9 \AA$, respectively. The loading of the protocatechuic acid anions within the LDH interlayers was determined based on the change in the interlayer $d$ spacing ( $d$ value). The interlayer $d$ spacing for the $\mathrm{LDH}$ after $\mathrm{Gd}$ and drug loading was determined to be $10.5 \AA$ from XRD data (Fig. 1d). However, the d value includes the thickness of the $\mathrm{Mg} / \mathrm{Al}-\mathrm{LDH}$ layer which was established to be $4.8 \AA$ (Cavani et al. 1991). Subtracting the LDH layer thickness value $(4.8 \AA)$, the actual $d$ value increase due to the drug and the contrast agent $(\mathrm{Gd})$ intercalation can be deduced as $10.5-4.8=5.3 \AA$. This confirms the process of intercalation

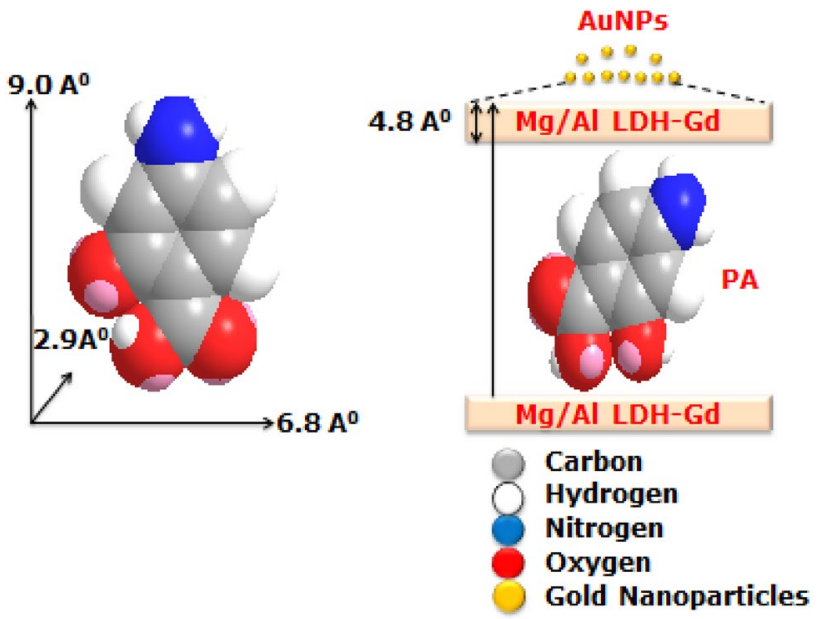

Fig. 2 The three-dimensional spatial orientation of protocatechuic acid and molecular structural model of protocatechuic acid and $\mathrm{Gd}$ intercalated between $\mathrm{Mg} / \mathrm{Al}$-layered double hydroxide as well as AuNPs adsorbed on the surface

has taken place via anionic loading. Furthermore, AuNPs can be seen on the LDH surface as the adsorbed guest species, suggesting the formation of a theranostic nanocomposite (Fig. 2).

In addition, the diffraction peak from the intercalated drug appears in the MAPGAu nanohybrid, although the intensity is much lower than in the MAPGA nanocomposite; suggesting the LDH-Gd structure after drug intercalation is still intact even after the growth of the gold nanoparticles. This is in agreement with the FESEM micrographs of the two nanocomposites, as will be discussed later.

\section{In vitro drug release study}

The in vitro release profiles of the protocatechuic acid obtained from the $\mathrm{Mg} / \mathrm{Al}-\mathrm{LDH}-\mathrm{Gd}$ nanocomposite (MAPGA) are shown in Fig. 3. The release data of the drug was acquired using a UV-Vis spectrophotometer in PBS media ( $\mathrm{pH} 4.8$ and 7.4). The profiles were obtained by matching the absorbances from the release, which are expressed in percentage against time of release; the release in both pHs varies at both time of release as well as the percentage of release. Although it is quite common and expected for guest molecules intercalated within LDH gallery to release more in the acidic medium than in the alkaline medium (Bullo and Hussein 2015; Usman et al. 2017a, b), as observed in this case (98\% at $\mathrm{pH} 4.8$ and $20 \%$ at $\mathrm{pH} 7.4$ ), it is, however, uncommon for the intercalated guest to vary in period of release at different $\mathrm{pHs}$. As can be observed in Fig. 3, the release in the alkaline medium ended at about halfway $(1500 \mathrm{~min})$ the time of release in the acidic $\mathrm{pH}$ (3000 min). This disparity could be attributed to the same 


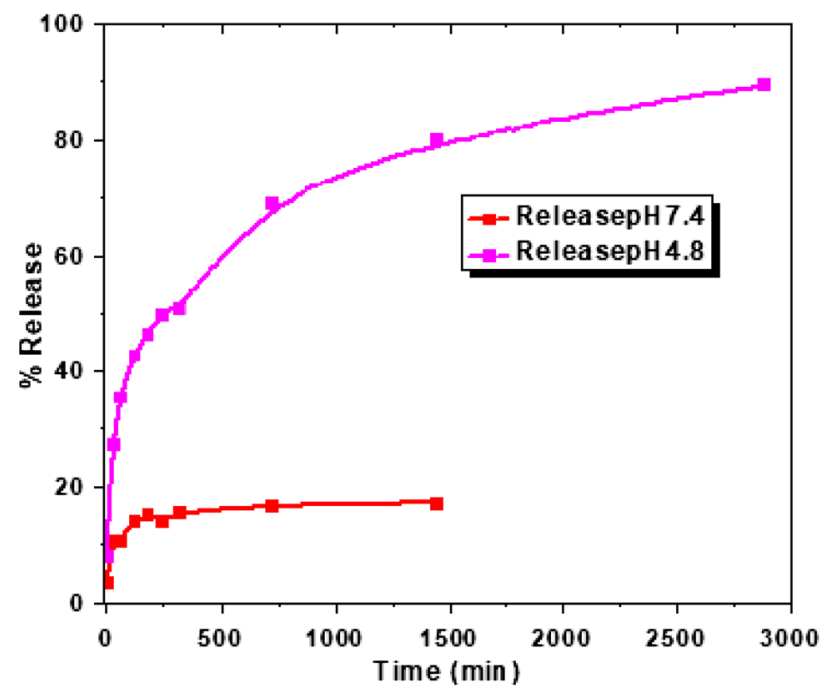

Fig. 3 Protocatechuic acid release profiles from Mg/Al-LDH-Gd nanocomposite in PBS media at $\mathrm{pH} 4.8$ and 7.4

reason for the higher release in the acidic medium, which is due total dissolution of the LDH nanocarrier in the acidic medium (Usman et al. 2017a, b). The dissolution is expected to happen along with the loaded guest, which allows the detachment of the electrostatically and hydrogen bonded drug to the LDH. Nevertheless, this in particular is of benefit in passive targeting of nano-drug delivery systems for anticancer purposes, because cancer cells have acidic $\mathrm{pH}$ (Sheng et al. 2013). This implies elongated and sustained release of the anticancer agent to the desired cancer region. In addition, the release profiles in both $\mathrm{pHs}$ indicate steady increase with time until the end. The method of the release study employed in this work is through sampling at selected time intervals, as described in the methodology section. The release pattern of the drug is indeed confirming the MAPGA XRD diffraction patterns, which indicates the intercalation of the PA into the LDH interlayers.

\section{Kinetic studies of the drug release}

There are three most commonly used kinetic models for drug release study, which are pseudo-first order, pseudo-second order and parabolic diffusion. The models are used to determine the most suitable kinetic pattern which best describes the complete drug release from the nanocarrier.
The models are calculated based on the variables obtained from the drug release data, the models equations are expressed below:

Pseudo-first order: $\ln \left(q_{e}-q_{t}\right)=\ln q_{t}-k t$

Pseudo-second order: $t / q_{t}=1 / k q_{e}^{2}+t / q$

Parabolic diffusion: $\left(1-M_{t} / M_{0}\right) / t=k t^{-0.5}+b$

The variables in some of the equations differ, for instance the pseudo-first and pseudo-second order are calculated based on the amount of drug release at equilibrium $\left(q_{e}\right)$ and the amount of drug release at specific time $\left(q_{t}\right)$, while the parabolic diffusion is derived from the drug content in the nanocarrier $\left(M_{t}\right.$ and $\left.M_{o}\right)$. The $t$ and $k$ in all the equations stand for time and release constant, respectively (Saifullah et al. 2013). The graphs are obtained from the plot of variables in the models, $\ln \left(q_{e}-q_{t}\right)$ against $t$ for pseudo-first order, $t / q_{t}$ against $t$ in pseudo-second order and $\left(1-M_{t} / M_{o}\right) / t$ against $t$ in parabolic diffusion. The correlation coefficients $\left(R^{2}\right)$ of the three models were deduced from the graphs and are presented in Table 1 along with rate constant $(K)$, percentage saturation $(\%)$ and $t_{1 / 2}(\mathrm{~min})$ of the sample in both pHs. The drug kinetic release data like several other reported kinetic release data of some drugs from different nano-carriers, was observed to have matched best to the pseudo-second order (Bullo and Hussein 2015; Bullo et al. 2013; Dorniani et al. 2012, 2014; Tan et al. 2014), with $R^{2}$ value of 0.982 (Fig. 4) against 0.560 and 0.695 for pseudo-first order and parabolic diffusion, respectively, in pH 4.8. Similarly, with even higher $R^{2}$ value (0.999) [Fig. 4], the release in $\mathrm{pH} 7.4$ fits best to the pseudo-second order, surpassing the pseudo-first order and the parabolic diffusion, which have $R^{2}$ values of 0.698 and 0.695 , respectively. Furthermore, the percentage saturation based on the percentage release of the drug was observed to be $95 \%$ at rate constant (k) $5.2 \times 10^{-2}$ for $\mathrm{pH} 4.8$ and $20 \%$ and at rate constant $1.1 \times 10^{-1}$ for $\mathrm{pH} 7.4$. The sharp contrast may suggest that substantial amount of the drug will be released in the cancer cells and minute amount in the blood stream. Further, the half-life of the theranostic nanocomposite (MAPGAu) was further determined at $60 \mathrm{~min}$, in the blood stream $\mathrm{pH} 7.4$ using PBS medium. This suggests faster and non-sustained

Table 1 Correlation coefficients $\left(R^{2}\right)$, percentage saturation, rate constant and $t_{1 / 2}$ (min) of protocatechuic acid kinetic release

\begin{tabular}{|c|c|c|c|c|c|c|c|}
\hline \multirow[t]{2}{*}{ Sample pH } & \multirow{2}{*}{$\begin{array}{l}\text { Percentage satu- } \\
\text { ration }(\%)\end{array}$} & \multirow[t]{2}{*}{ Rate constant $(k)$} & \multirow[t]{2}{*}{$\boldsymbol{t}_{1 / 2}(\min )$} & \multirow{2}{*}{$\begin{array}{l}\text { MAPGAu, } t_{1 / 2} \\
(\min )\end{array}$} & \multicolumn{3}{|c|}{ Correlation coefficients $\left(R^{2}\right)$} \\
\hline & & & & & Pseudo-first order & $\begin{array}{l}\text { Pseudo-second } \\
\text { order }\end{array}$ & $\begin{array}{l}\text { Parabolic } \\
\text { diffusion }\end{array}$ \\
\hline 7.4 & 20 & $1.1 \times 10^{-1}$ & 120 & 60 & 0.698 & 0.999 & 0.396 \\
\hline 4.8 & 95 & $5.2 \times 10^{-2}$ & 150 & - & 0.560 & 0.982 & 0.695 \\
\hline
\end{tabular}


release when compared with the drug release. The variation is influenced by the surface adsorption of the contrast agents.

\section{Fourier-transformed infrared spectroscopy}

The fourier-transformed infrared spectroscopy (FTIR) spectra of the LDH nanocarrier, the pure drug, $\mathrm{Gd}\left(\mathrm{NO}_{3}\right)_{3}$ and the resultant nanocomposites (MAPGA and MAPGAu) were studied to understand the chemical interactions that took place at the composites level. As can be seen in the $\mathrm{Gd}\left(\mathrm{NO}_{3}\right)_{3}$ spectrum (Fig. 5a), the $\mathrm{OH}$ stretching vibration bands are observed at 3453 and $3187 \mathrm{~cm}^{-1}$ (Bi et al. 2014), $\mathrm{H}_{2} \mathrm{O}$ bending vibration is at $1650 \mathrm{~cm}^{-1}$ (Eisenberg and Kauzmann 2005); the $\mathrm{NO}_{3}$-stretching vibrations are at 1444 and $1314 \mathrm{~cm}^{-1}$ (Sun et al. 2010). In the Mg/Al-LDH spectrum in Fig. 5b, all the absorption bands appear to be in the region of low wavenumbers, the $\mathrm{OH}$ stretching vibration is observed at $3469 \mathrm{~cm}^{-1}$ (Bi et al. 2014). The bands at 1642 , 1372, 966 and $492 \mathrm{~cm}^{-1}$, are representative of $\mathrm{H}_{2} \mathrm{O}$ bending vibrations (Eisenberg and Kauzmann 2005), $\mathrm{NO}_{3}$-stretching vibration (Sun et al. 2010), M-O and O-M-O lattice vibration modes (Aisawa et al. 2006), respectively. The pure protocatechuic acid is shown in Fig. 3c, two O-H bands can be observed, one at $3542 \mathrm{~cm}^{-1}$ and a broad band at $3187 \mathrm{~cm}^{-1}$ (Bi et al. 2014). The $\mathrm{C}=\mathrm{O}$ stretching vibration bands can be seen at $1642 \mathrm{~cm}^{-1}$ as well as at $1291 \mathrm{~cm}^{-1}$, which are due to the presence of carboxyl group of the drug. The band at $1495 \mathrm{~cm}^{-1}$ could be attributed to stretching modes of $\mathrm{C}-\mathrm{C}$ aromatic ring (Barahuie et al. 2013), while the bands

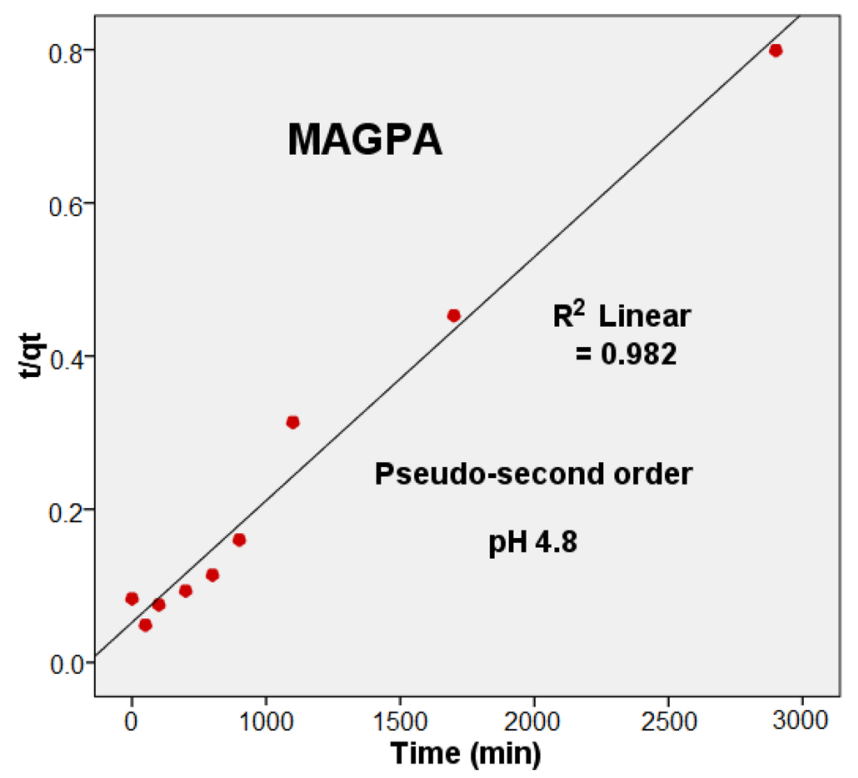

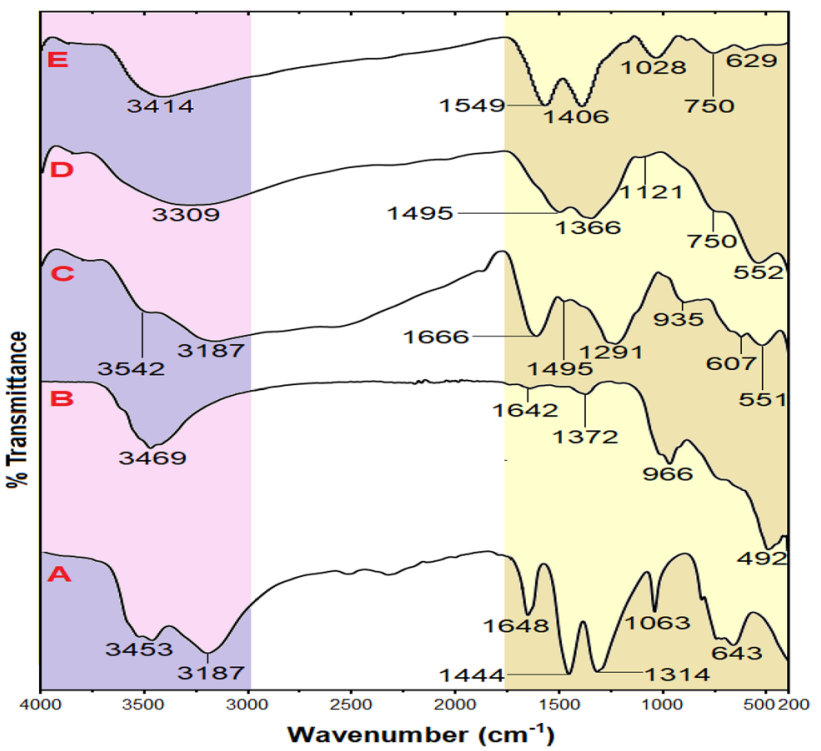

Fig. 5 FTIR spectra of a pure $\operatorname{Gd}\left(\mathrm{NO}_{3}\right)_{3}$, b $\mathrm{Mg} / \mathrm{Al}-\mathrm{LDH}$, c pure protocatechuic acid, d drug-intercalated $\mathrm{Mg} / \mathrm{Al}-\mathrm{LDH}-\mathrm{Gd}$ nanocomposite (MAPGA), e drug-intercalated $\mathrm{Mg} / \mathrm{Al}-\mathrm{LDH}-\mathrm{Gd}$ coated with AuNPs (MAPGAu)

between 935 and $551 \mathrm{~cm}^{-1}$ are all linked to the $\mathrm{OH}$ bending vibrations of the carboxylic group of the drug.

In the case of the nanohybrid spectra (Fig. 3d, e), it can be observed the various band shifts due to chemical interactions that transpired in comparison with the spectra of the pristine starting materials. For instance, in the protocatechuic acidintercalated Mg/Al-LDH nanocomposite (MAPGA) spectrum in Fig. 3d, all the absorptions appear to have shifted to

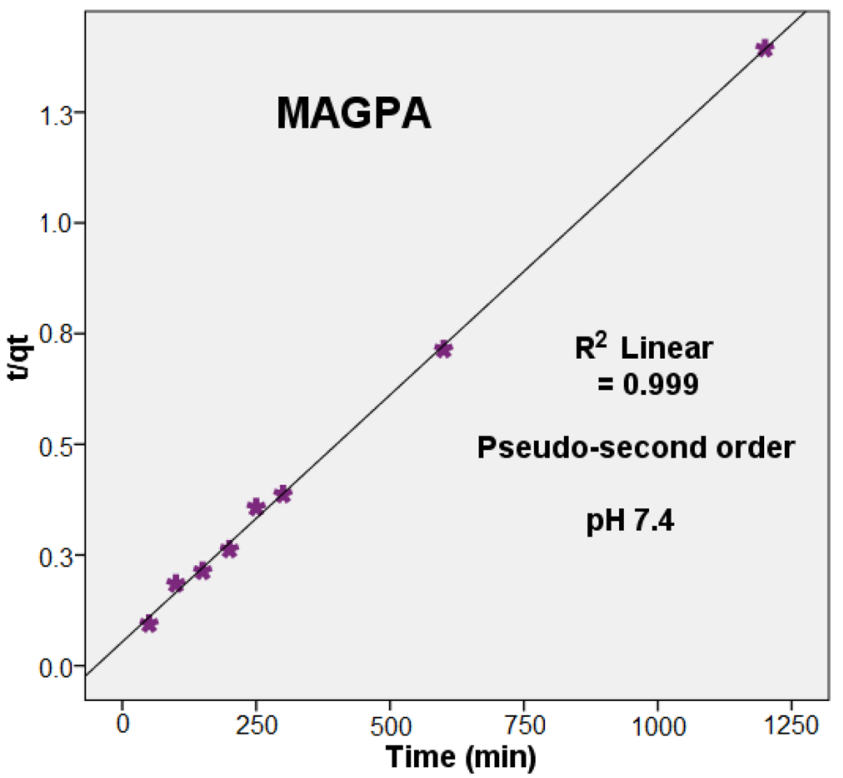

Fig. 4 Protocatechuic acid kinetic fitting of release data from Mg/Al-LDH-Gd nanocomposite in PBS media at pH 4.8 and 7.4 
lower wavenumbers, starting with the $\mathrm{OH}$ band that moved to $3308 \mathrm{~cm}^{-1}$; the carboxyl functional group bands at 1642 and $1291 \mathrm{~cm}^{-1}$ are observed to be missing, which is presumably due to the hydrogen bonding that occurred between the host nanocarrier and the guest drug. Further, the $\mathrm{C}-\mathrm{C}$ aromatic ring stretching modes absorption did not change as in the PA spectrum $\left(1495 \mathrm{~cm}^{-1}\right)$; and the newly formed symmetric stretching band of $\mathrm{COO}^{-}$was also observed at $1366 \mathrm{~cm}^{-1}$. The $\mathrm{OH}$ bending vibration bands also appear to be repositioned because of the interlayer interactions (607 and $551 \mathrm{~cm}^{-1}$ ). Consequently, the AuNPs-coated LDH/ Gd/PA nanocomposite (MAPGAu) spectrum is similar to MAPGA nanocomposite with stronger absorption bands as a result of the increase in water molecular movement within the LDH matrix (Caravan 2006). The significant difference between the MAPGA and MAPGAu spectra (Fig. 3d, e) is the strong carboxylate vibration $\left(\mathrm{COO}^{-}\right)$that appeared at
$1549 \mathrm{~cm}^{-1}$ in the MAPGAu spectrum (Aisawa et al. 2006), which is likely due to anion exchange and electrostatic interaction between the MAPGA nanohybrid and the AuNPs adsorbed on the surface. The above mentioned interaction is majorly responsible for the contrast enhancement in MR imaging of the nanocomposites, as will be discussed later in MRI studies.

\section{Thermal properties studies}

The thermal analysis of the starting materials in their pure forms and the subsequent nanocomposites obtained from the intercalation and adsorption of the various guest materials have been conducted using TGA/DTG analyses. The thermogram depicted in Fig. $6 \mathrm{a}$ is for the $\mathrm{Mg} / \mathrm{Al} \mathrm{LDH}, \mathrm{b}$ for the pure protocatechuic acid, $\mathrm{c}$ for the protocatechuic acid-intercalated LDH-Gd (MAPGA), and d for the AuNPs-coated
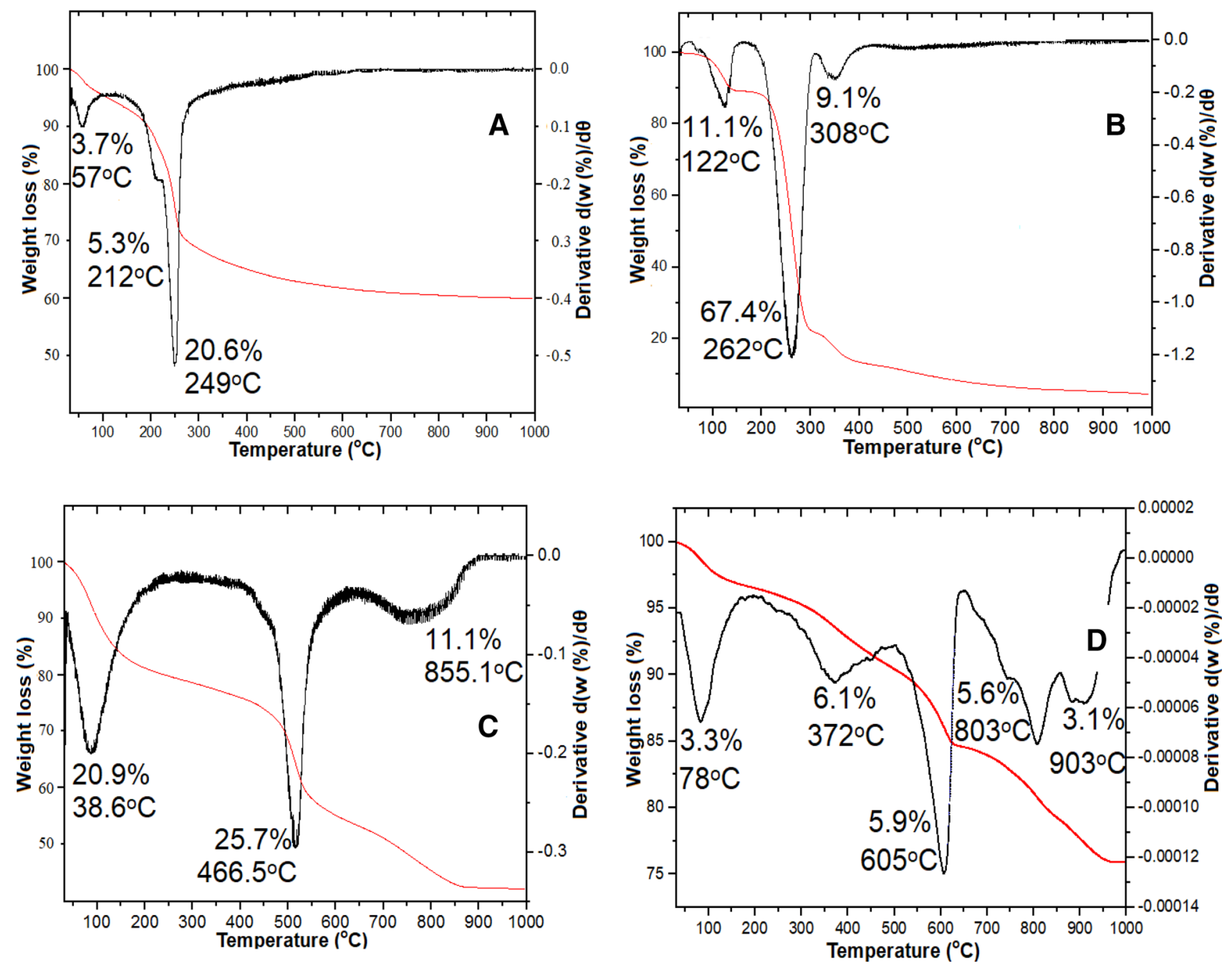

Fig. 6 TGA thermograms of a Mg/Al-LDH, b pure protocatechuic acid, $\mathbf{c}$ drug-intercalated Mg/Al-LDH-Gd nanocomposite (MAPGA), d drug-intercalated Mg/Al-LDH-Gd coated with AuNPs (MAPGAu) 
nanocomposite after drug intercalation (MAPGAu). The $\mathrm{LDH}$ thermogram shows a major decomposition at $249{ }^{\circ} \mathrm{C}$ that corresponds with $20 \%$ weight loss, which is due to the decomposition of the hydrotalcite-like material. The other two decompositions are due to the absorbed moisture $\left(57{ }^{\circ} \mathrm{C}\right.$ and $3.7 \%$ weight loss) and impurities $\left(212{ }^{\circ} \mathrm{C}\right.$ and $5.3 \%$ weight loss). Similarly, the protocatechuic acid thermogram shows three decompositions (Fig. 6b), from 122 to $308{ }^{\circ} \mathrm{C}$. Like several reported thermograms, the thermal events always begin with the elimination of absorbed water within the range of $25-122{ }^{\circ} \mathrm{C}$ (Barahuie et al. 2014) and weight loss of $11.1 \%$. Successively, the major decomposition of PA occurred at $262{ }^{\circ} \mathrm{C}$ and weight loss $67.4 \%$ (Barahuie et al. 2017). Lastly, the residue decomposed at $308^{\circ} \mathrm{C}$ with a weight loss of $9.1 \%$.

The thermograms of the nanocomposites are as expected different from those of the starting materials, which have more decomposition at elevated temperatures. As can be seen in Fig. 6c for MAPGA nanocomposite, the first decomposition at $38{ }^{\circ} \mathrm{C}$ with weight loss of $20.9 \%$ is attributed to the loss of structured and physisorbed water, through internal and external means. The decomposition at $446{ }^{\circ} \mathrm{C}$ with a weight loss of $25.7 \%$ is the second and major decomposition stage, and is ascribed to simultaneous hydroxide layer dehydroxylation alongside the intercalated guests (protocatechuic acid, Gd and nitrate ions); the residue pick can be observed at $855^{\circ} \mathrm{C}$ with a weight loss of $11.1 \%$. The major decomposition of protocatechuic acid occurred at $262{ }^{\circ} \mathrm{C}$ and de-hydroxylation of LDH layers at $249^{\circ} \mathrm{C}$ in their pristine states, which can be seen to have shifted to $446{ }^{\circ} \mathrm{C}$ in the MAPGA nanocomposite. This suggests improved thermal stability due to the electrostatic attraction of carboxylate group and the hydrogen bonding that occurred between the drug and the host LDH nanolayers (Barahuie et al. 2013), as observed earlier in the FTIR analysis.

The final MAPGAu nanocomposite obtained after surface adsorption of AuNPs (Fig. 6d), shows even more thermal stability in certain cases than in the MAPGA thermogram. For instance, the protocatechuic acid decomposition that occurred at $446{ }^{\circ} \mathrm{C}$ in MAPGA shifted to higher temperature in MAPGAu $\left(605^{\circ} \mathrm{C}\right.$ and weight loss $\left.5.9 \%\right)$. However, the de-hydroxilation decomposition of the LDH layers in MAPGAu occurred at slightly lower temperature $\left(372{ }^{\circ} \mathrm{C}\right)$ than in the MAPGA $\left(466^{\circ} \mathrm{C}\right)$; but higher than in the pure $\mathrm{LDH}\left(249^{\circ} \mathrm{C}\right)$. The variation is a direct result of the nature of electrostatic attraction between AuNPs and the LDH-Gd layers (King et al. 2016). Nevertheless, the nanohybrids appear to be more stable thermally, than in their pure phases.

\section{Morphological and elemental composition studies}

The surface morphology and elemental composition of the nanocomposites were studied by the combination of FESEM and EDS analyses, which were focused on the drug-intercalated LDH-Gd nanocomposite (MAPGA) and the AuNPscoated nanocomposite (MAPGAu). The micrograph of MAPGAu nanohybrid (Fig. 7a) shows fair distribution of AuNPs at $100,000 \times$ magnification, directly adsorbed on the LDH-Gd nanolayers. The nanoparticles are predominantly spherical in shape and small in size as evident from the figure. Further, the micrograph is in agreement with the earlier discussed XRD diffractogram of the sample (Fig. 1e), which depicts the reflections of pure AuNPs after surface adsorption through electrostatic interactions (Uppal et al. 2013). The MAPGA nanohybrid (Fig. 7b) on the other hand can be seen to show only the drug-intercalated into the LDH matrix, with slight agglomeration of the nanocomposite. The EDS spectra of both nanocomposites were obtained from the micrographs of the individual samples through random scan of the various areas of the micrographs. As expected, the MAPGAu spectrum (spectrum i) indicates peaks from the various elements contained in the LDH-Gd nanocarrier with prevailing signals coming from the AuNPs; this is an indication of surface adsorption of the AuNPs on the LDH surface, as indicated in the XRD reflections of the sample. The MAPGA spectrum (spectrum ii) shows all similar elemental composition with MAPGAu, only the Au signals are absent.

This is predictable outcome since the MAPGA EDS analysis was done before the AuNPs doping. It can be deduced from the results of FESEM and EDS of both nanocomposites that the LDH was actually formed and the guests' molecules were sequentially intercalated (Gd and PA) and the AuNPs were adsorbed on the LDH-Gd surface. These studies also suggest that the nanohybrids are relatively of pure phase as other impurity reflections were not observed in both spectra.

\section{Shape and particles size distribution studies}

The nanocomposites were studied using transmission electron microscopy (TEM) to fathom the size and distribution of the AuNPs grown on the LDH-Gd nanocomposite. Figure 8 depicts the TEM micrographs of MAPGAu (a) and MAPGA (b). The MAPGAu nanocomposite appears to have spherical-shaped AuNPs directly grown on the LDH surface. The sizes of the nanoparticles are predominantly within the small range (5-30), as indicated by the size distribution histogram. However, some few nanoparticles appear to have larger particle sizes, mostly within the range $90-120 \mathrm{~nm}$. The large nanoparticles are agglomerated from smaller nanoparticles, which bind together due high surface energy between the individual nanoparticles (Raffi et al. 2010; Usman et al. 2012). The direct deposition of the AuNPs on the LDH surface layers is an indication of the electrostatic interaction acting between them, which is vital to the MRI signal amplification. The interaction was earlier observed in the XRD of the MAPGAu nanocomposite and subsequently 
Fig. 7 FESEM micrographs of a drug-intercalated $\mathrm{Mg} / \mathrm{Al}-$ LDH-Gd coated with AuNPs (MAPGAu), b drug-intercalated $\mathrm{Mg} / \mathrm{Al}-\mathrm{LDH}-\mathrm{Gd}$ nanocomposite (MAPGA) and EDS spectra of (i) drug-intercalated $\mathrm{Mg} / \mathrm{Al}-\mathrm{LDH}-\mathrm{Gd}$ coated with AuNPs (MAPGAu), (ii) drugintercalated $\mathrm{Mg} / \mathrm{Al}-\mathrm{LDH}-\mathrm{Gd}$ nanocomposite (MAPGA)
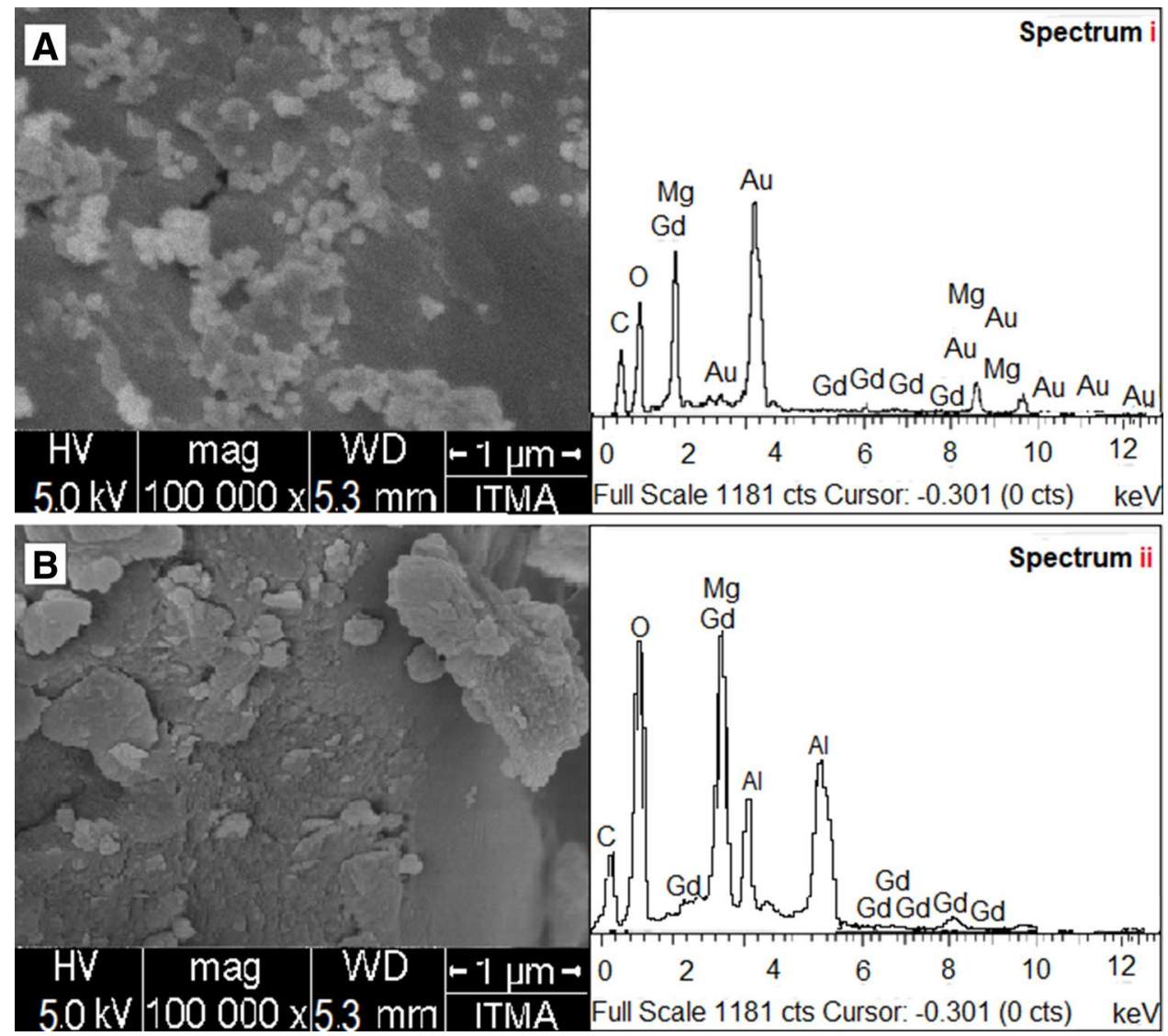

in the FTIR spectrum and FESEM results, which all have been discussed earlier. The micrograph (b) is of the MAPGA nanocomposite, that is, the LDH compacted together with the protocatechuic acid intercalated into the LDH intergallery. Similar observation has been previously reported, where LDH was used to load anticancer agents (Barahuie et al. 2012, 2013).

\section{In vitro elemental composition studies}

The elemental composition of the nanocomposites was determined by a combination of ICP-OES and CHNS analyses, presented in form of percentages. The latter was used for carbon and hydrogen content determination, whilst the former was utilised for the metallic content estimation in the nanohybrids. Table 2 presents a compilation of both analyses; it can be observed from the ICP-OES results of the pure $\mathrm{LDH}$, only the $\mathrm{Mg}(7.3 \%)$ and $\mathrm{Al}(4.5 \%)$ elements were detected, which are the main components of the LDH. This is indicative of the initial formation of the MgAl-LDH nanocarrier as indicated in Fig. 1c of the XRD diffractograms and the EDS (spectrum ii) of the sample. The ICPOES results of MAPGAu nanocomposite equally indicate the presence of $\mathrm{Mg}$ and $\mathrm{Al}$ although at lower percentages, 3.7 and $0.3 \%$, respectively; due to chemical interactions with the guest molecules. Other elements, such as Gd (2.4\%) and $\mathrm{Au}(1.8 \%)$ which were loaded at different stages of the experiment can also be observed in the ICP-OES data. In addition, the protocatechuic acid carbon reflection was also detected in MAPGAu CHNS analysis result, which further affirms the intercalation of the drug. The results obtained in these analyses are in line with the previous experiments reported earlier, particularly the EDS analysis. The results confirm the interlayer bonding between the drug and LDH host. In the case of MAPGAu, surface adsorption of the AuNPs is also confirmed.

\section{In vitro cytotoxicity and anticancer activity studies}

Since one of the major potential uses of our developed nanocomposite is for cancer chemotherapy, it is important to investigate the anticancer efficacy as well as the cytotoxicity of the MAPGAu nanocomposite to normal cells. We have used breast cancer cell lines (HepG2) to investigate the anticancer properties and normal fibroblast cell line (3T3) for the cytotoxicity test. The efficacy test was conducted using the pure protocatechuic acid, the as synthesized LDH nanocarrier and the last stage nanocomposite (MAPGAu). Figure 9 is a histogram representation of the efficacy data for the aforementioned samples against HepG2 and 3T3 cell 

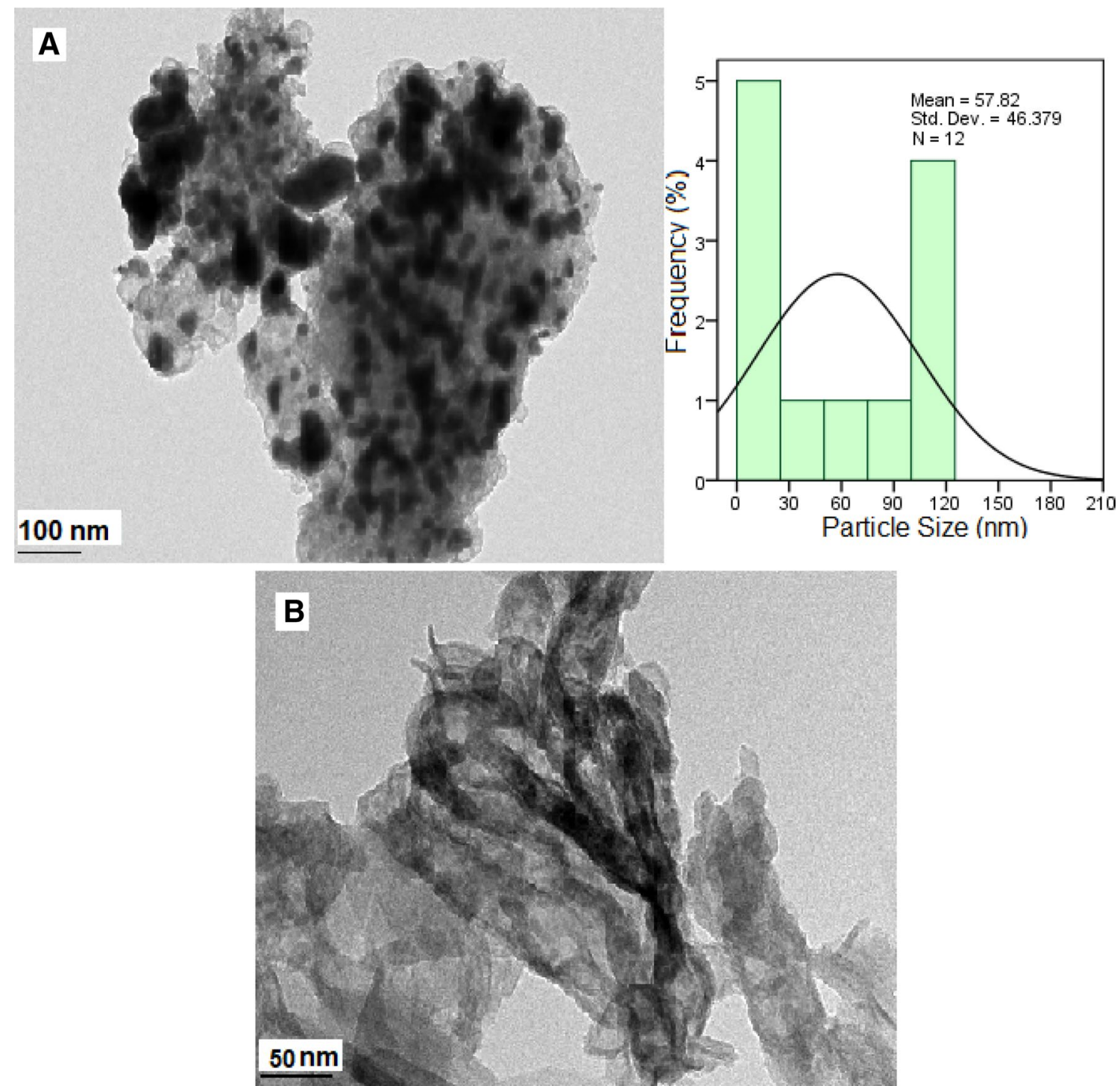

Fig. 8 TEM micrographs of a drug-intercalated Mg/Al-LDH-Gd coated with AuNPs (MAPGAu) and b drug-intercalated Mg/Al-LDH-Gd nanocomposite (MAPGA)

Table 2 Elemental composition of the theranostic delivery system

\begin{tabular}{lllllll}
\hline Sample & $\mathrm{Gd} \% * *$ & $\mathrm{Mg} \%^{* *}$ & $\mathrm{Al} \%^{* *}$ & $\mathrm{Au} \% * *$ & $\mathrm{C} \% *$ & $\mathrm{H} \%^{*}$ \\
\hline LDH & - & 7.3 & 4.5 & - & - & - \\
MAPGAu & 2.4 & 3.7 & 0.2 & 1.8 & 13.6 & 3.4 \\
\hline
\end{tabular}

*Results estimates from CHNS analysis

**Results estimates from ICP-OES analysis lines. It can be deduced from the anticancer efficacy studies, the protocatechuic acid activity increases progressively as the dose. The $\mathrm{Mg} / \mathrm{Al} \mathrm{LDH}$ nanocarrier did not indicate any significant activity. This is expected as LDHs are not known to have anticancer properties; therefore, the cancer cells would not be susceptible to it. The MAPGAu agent shows similar pattern of activity with the pure drug from
0 to $100 \mu \mathrm{g} / \mathrm{mL}$ dose. The $100 \mu \mathrm{g} / \mathrm{mL}$ dose of the MAPGAu nanohybrid appears to be the most effective against the HepG2 cancer cells, which makes the HepG2 cells most susceptible to MAPGAu at $100 \mu / \mathrm{mL}$. The anticancer activity occurs via electrostatic attraction towards the cell surfaces that are negatively charged, which influences the cellular uptake of MAPGAu nanohybrid by the cancer cells. The 
Fig. 9 Cell viability results of LDH-Gd loaded with protocatechuic acid and AuNPs (MAP$\mathrm{GAu}$ ), pure protocatechuic acid and the LDH nanocarrier tested with cancer cell lines (HepG2) and normal fibroblast cell lines (3T3)
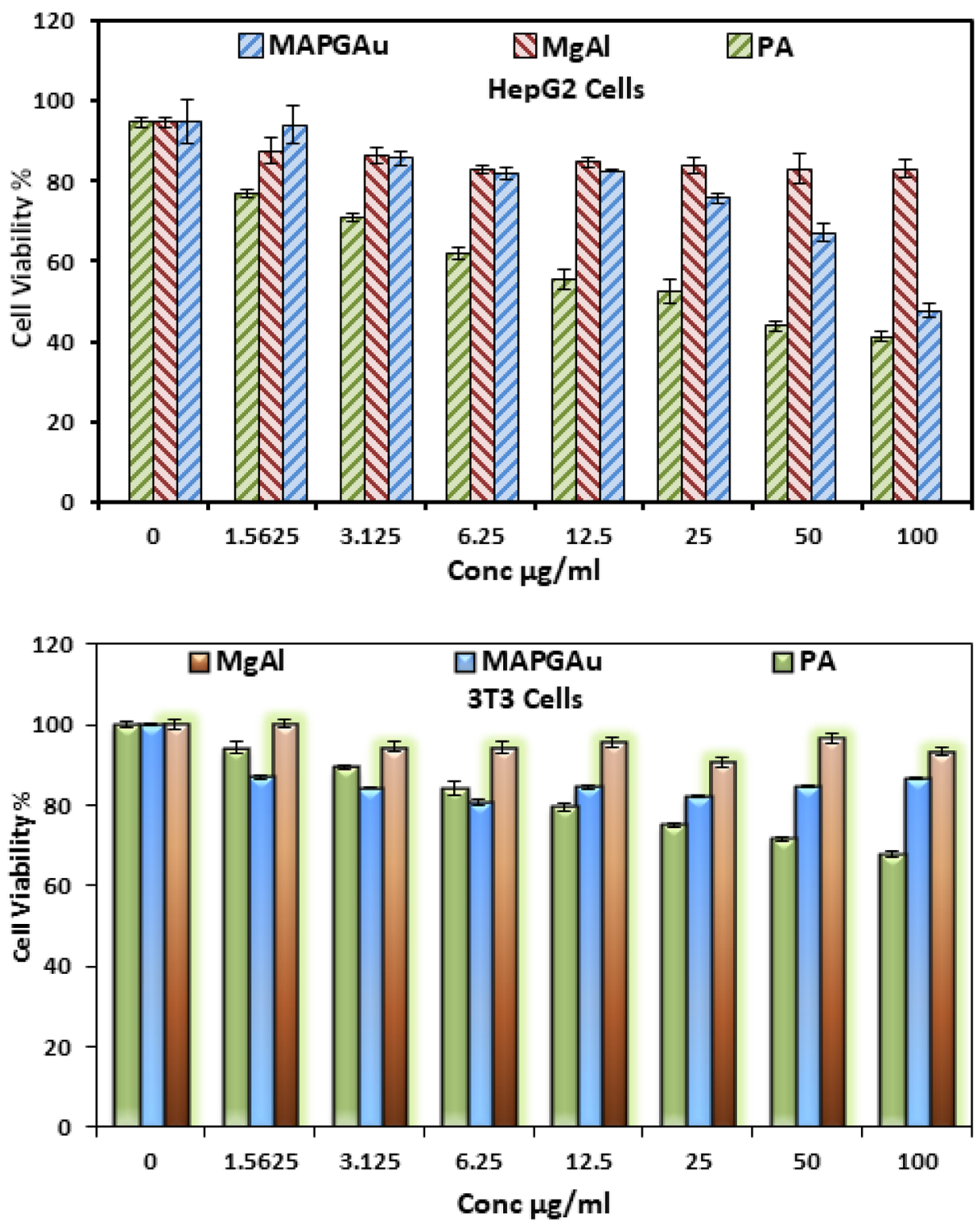

process is known as cellular endocytosis (Kura et al. 2014). Protocatechuic acid-based nanocomposites have previously been reported to have higher anticancer activity in other cancer cells (Barahuie et al. 2013), which suggest this nanocomposite could equally have higher efficacy in other cancer cell lines such as HeLa and HT29 cancer cells.

Figure 9 equally presents the cytotoxicity data of the LDH nanocarrier, the MAPGAu nanocomposite and the pure protocatechuic acid. From the cell growth chart, the toxicities expressed by nanocarrier and the nanocomposite could be considered insignificant to cause any to harm to the normal cells. All the tested doses show similar outcomes towards the 3T3 cells. This underscores the appropriateness of $\mathrm{Mg} / \mathrm{Al}$ $\mathrm{LDH}$ as a drug delivery agent. As for the drug, the toxicity is found to follow the same trend with its anticancer efficacy, which was observed to increase proportionally as the dose. Nonetheless, the natural product-based anticancer agent is also nontoxic to normal cells. This buttresses the choice of protocatechuic acid as the model anticancer agent in this research against the conventional toxic anticancer agents (RxList 2016).

It is remarkable to note that the MAPGAu nanohybrid, which contains Gd contrast agent and is considered relatively as a toxic substance (Thomsen 2006), did not show significant cytotoxicity to normal cells in the composite form. This is because the toxicity has been neutralized by the LDH nanocarrier, which supports the suitability of the nanocomposite as a safe theranostic agent.

\section{Contrast enhancement}

The AuNPs-coated LDH-Gd/PA (MAPGAu) nanohybrid was tested with magnetic resonance imaging (MRI) equipment to determine its diagnostic properties. The 
theranostic MAPGAu nanohybrid was prepared into various $\mathrm{Gd}^{3+}$ concentrations of aqueous solutions in $1 \mathrm{~mL}$ tubes. The tubes were placed in the 3.0 T MRI machine. Prior to that, the tubes were tagged to the MRI calibration phantom in the order; MAPGAu solution $(2.0,0.5$ and $0.2 \mathrm{w} / \mathrm{v})$ concentration, $\mathrm{Gd}\left(\mathrm{NO}_{3}\right)_{3}(0.5 \mathrm{w} / \mathrm{v})$ concentration and water reference (total of five tubes). The obtained recorded image of the tubes was studied with Syngovia MRI analysis software, after which the mean signals of the individual tubes were documented (Fig. 10). The physical difference between the tubes as arranged according to the varied concentrations can be seen. The brightness in the T1-weighted image of the tubes is observed to increase as the $\mathrm{Gd}^{3+}$ concentration, whilst the $\mathrm{Gd}$ and water reference show the least contrast; this is an indication of $\mathrm{T} 1$ and $\mathrm{T} 2$ signals increment. In addition, the signal enhancement can be confirmed by the measured means of the individual tubes, which similarly shows steady rise in the values from high to low concentrations $(2.0,0.5$ and 0.2$)$ and the least to be Gd and water $(833.73,800.99,614.41,235.4$ and 228.66, respectively). Similar outcome has been reported previously by Wang et al. 2013, who used Gd-based nanocomposite for MRI contrast studies. The working theory behind the signal boost is due to improved intermolecular movements of water molecules within the $\mathrm{LDH} / \mathrm{Gd}^{3+}$ gallery which can be ascribed to increase in surface area in the entire nanocomposite (Wang et al. 2013). The rise in the surface is as a result of the surface coating of the AuNPs, through which the water molecular interaction is raised. Moreover, the process shortens the T1 signal (longitudinal relaxation time) and eventually the generated T1-weighted image signal is enhanced (Usman et al. 2017a, b).

\section{Conclusion}

In this work, therapeutic and diagnostic agents were successfully loaded on the same nanocarrier for theranostic application. Gadolinium as the contrast agent was first intercalated into the $\mathrm{LDH}$ interlayers to form $\mathrm{LDH}-\mathrm{Gd}$, followed by intercalation of protocatechuic acid into the $\mathrm{LDH}-\mathrm{Gd}$ interlayer gallery as confirmed by XRD diffractograms. Gold nanoparticles were subsequently adsorbed on the as prepared protocatechuic acid-intercalated LDH-Gd nanocomposite. The XRD diffractograms together with other characterization results conducted in this report confirmed the surface coating of the drug LDH-Gd (MAPGA) nanocomposite with AuNPs, which was done at the last stage of the synthesis series (MAPGAu). The drug release studies of the theranostic nanocomposite showed high and prolong release of the therapeutic active agent at $\mathrm{pH} 4.8$, which is the $\mathrm{pH}$ of the cancer cells. However, the release was less than $20 \%$ and ended just after $1500 \mathrm{~min}$ in the $\mathrm{pH}$ 7.4. This complements the intended theranostic delivery application of the nanohybrid, which was further examined with HepG2 cancer cell lines and 3T3 normal cell lines for the therapeutic component. The efficacy of the nanocomposite against the 3T3 cell lines showed no relative cytotoxicity in all the tested concentrations. The HepG2 showed the highest susceptibility at $100 \mu \mathrm{g} / \mathrm{mL}$ dose of the MAPGAu nanocomposite. The cytotoxicity assay results show MAPGAu is a nontoxic anticancer agent. The diagnostic counterpart of the MAPGAu nanocomposite was tested as contrast enhancer for T1-weighted MRI images. The MAPGAu was varied into Gd concentrations, which all showed higher T1 signals than pure $\mathrm{Gd}$ and the water references. The lowest MAPGAu
Fig. 10 T1-weighted image of the protocatechuic acid-loaded LDH/Gd-AuNPs nanohybrid (MAPGAu) taken from MRI Prisma 3-Tesla machine at varied concentrations of $\mathrm{Gd}^{3+}$ (2.0, 0.5 and 0.2), Gd (0.5) w/v and water

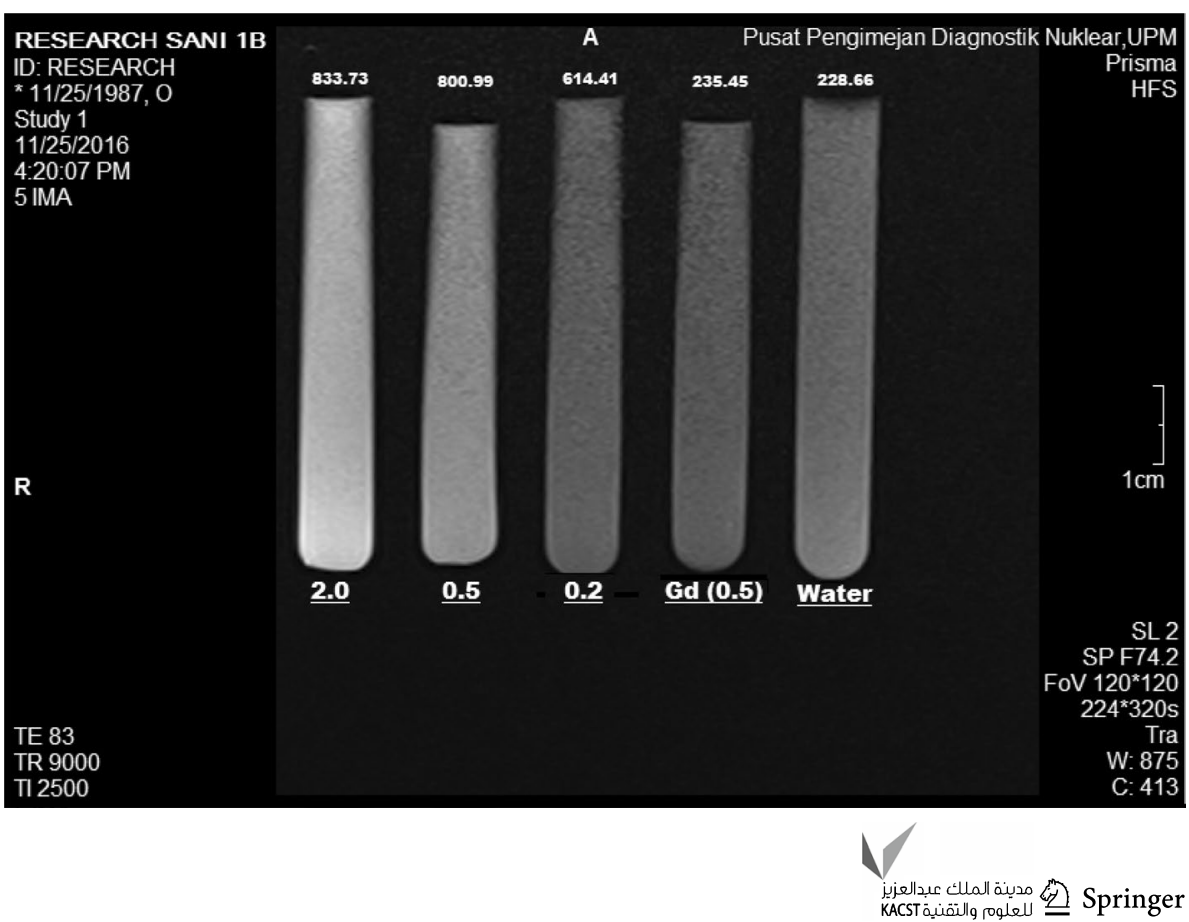


concentration used $(0.2 \mathrm{w} / \mathrm{v})$ gave higher signal when compared to both $\mathrm{Gd}$ at $0.5 \mathrm{w} / \mathrm{v}$ concentration and water.

Based on the aforementioned results from the therapeutic and the diagnostic test conducted, it is conclusive that the theranostic nanocomposite established in this work has prospects to be useful in the quest for future universal cancer treatment therapy. The promising result of our preliminary studies could be further worked upon especially in the area of in vivo and animal studies.

\section{Materials and methods}

\section{Materials}

The chemicals and reagents and their molecular weights (MW) and percentage purities (PP) used in this work are presented in this chapter. All the reagents were used directly as received and milli $Q$ water was used all through the synthesis.

Sodium borohydride (MW $37.83 \mathrm{~g} / \mathrm{mol}$, PP 99\%) was supplied by Fluka Analytical (St. Gallen, Switzerland). Gadolinium (III) nitrate hexahydrate (MW $451.4 \mathrm{~g} / \mathrm{mol}$, PP 99.9\%), tetrachloroauric (III) acid trihydrate (MW $393.83 \mathrm{~g} /$ mol, PP 49\% Au) were supplied by Acros Organics (NJ, USA) and magnesium nitrate hexahydrate (MW 297.47 g/ mol, PP 99\%) was procured from Acros Organics (Geel, Belgium). Aluminium nitrate hexahydrate (MW $375.13 \mathrm{~g} / \mathrm{mol}$, PP 98\%) was supplied by Systerm ChemPur (Shah Alam, Selangor Darul Ehsan Malaysia). Protocatechuic acid (MW $170.12 \mathrm{~g} / \mathrm{mol}$ and PP 98\%), phosphate-buffered saline (PBS) and sodium hydroxide (MW $40.00 \mathrm{~g} / \mathrm{mol}$, PP 98\%) was supplied by Sigma-Aldrich (St. Louis, MO).

\section{Synthesis of Gd-Mg/Al-layered double hydroxide and intercalation of protocatechuic acid}

The LDH was synthesized and the anticancer agent as well as $\mathrm{NaOH}(2 \mathrm{M})$ were loaded simultaneously as previously described by Barahuie et al. 2014 using the co-precipitation or direct method. However, $\mathrm{Gd}\left(\mathrm{NO}_{3}\right)_{3}(0.0008 \mathrm{M})$ was added to the initially prepared $\mathrm{Mg}\left(\mathrm{NO}_{3}\right)_{2}$ and $\mathrm{Al}\left(\mathrm{NO}_{3}\right)_{3}$ (molar ratio of 4:1) of $\mathrm{Mg}^{2+}$ to $\mathrm{Al}^{3+}$ solution. All the other protocols were followed as exactly described in the paper.

\section{Loading of AuNPs in protocatechuic acid-Gd-Mg/ Al-layered double hydroxide}

The already prepared MAPGA sample above was re-dispersed into $30 \mathrm{~mL}$ of deionized water using a sonicator (10 min). A $2 \% \mathrm{HAuCl}_{4}$ solution was prepared from the stock solution and $6 \mathrm{~mL}$ was added to the MAGPA solution. While stirring and heating at $60{ }^{\circ} \mathrm{C}, 2 \mathrm{~mL}$ of $0.25 \mathrm{M} \mathrm{NaOH}$ was added and the mixture was kept for $24 \mathrm{~h}$. The precipitate obtained was re-dispersed into deionized water. Prior to that, the precipitate was filtered and $20 \mathrm{~mL}$ of reducing agent $\left(1 \mathrm{M} \mathrm{NaBH}_{4}\right)$ was introduced into the dispersion. The mixture was stirred for $1 \mathrm{~h}$ after which it was washed and dried at $70{ }^{\circ} \mathrm{C}$ in a vacuum oven.

\section{Characterization}

PXRD analysis was conducted on a Shimadzu X-ray diffractometer (XRD) (XRD-6000, Tokyo, Japan) at $2-70^{\circ} \theta$ range, $4^{\circ} \theta / \mathrm{min}$ speed, $30 \mathrm{kV}$ and $30 \mathrm{~mA}$ using $\mathrm{CuK}_{\alpha}$ radiation $(\lambda=1.5418 \AA)$. Carbon, hydrogen, nitrogen and sulphur (CHNS) analysis was conducted on a LECO CHNS-932 (model Optima2000DV). Drug release study was done with a Lambda35 Perkin-Elmer ultraviolet-visible spectrophotometer (UV/Vis), while a Perkin-Elmer spectrophotometer (model Optima2000DV) was used for inductively coupled plasma-atomic emission spectrometry (ICP-OES) composition analysis.

Fourier transform infrared spectroscopy (FTIR) was done on a Thermo Nicolet Nexus FTIR (model Smart Orbit), using the $\mathrm{KBr}$ disc method, and the sample pellets were pressed at 10 ton and the spectra was obtained at $400-4000 \mathrm{~cm}^{-1}$ range. Thermogravimetric and differential thermogravimetric (TGA/DTG) analyses were done on a Mettler-Toledo instrument at $10^{\circ} \mathrm{C} / \mathrm{min}, 20-1000{ }^{\circ} \mathrm{C}$ range and $50 \mathrm{~mL} / \mathrm{min}$ flow rate of nitrogen. High resolution transmission electron microscopy (HRTEM) and field emission scanning electron microscopy (FESEM) analyses were done on a FEI Tecnai (TF20 X Twin) and a FEI Nova (NanoSEM 230) FEI, Hillsboro, OR, USA, respectively, for shape, sizes and morphology studies. The energy dispersive X-ray spectrophotometer (EDS) was connected to the FESEM and was used as complementary analysis for composition studies.

\section{Drug release}

Six standard concentrations of protocatechuic acid were prepared from a stock solution and were used for standard curve calibration. The lambda max $\left(\lambda_{\max }\right)$ of the pure drug was obtained at $259 \mathrm{~nm}$ using a Lambda $35 \mathrm{UV}-\mathrm{Vis}$ spectrophotometer. For loading and release study, adequate amount of the nanocomposite was dissolved in $\mathrm{HCl}(1 \mathrm{~mol} / \mathrm{L})$ solution and diluted with deionized water $(45 \mathrm{~mL})$. For the release study, $25 \mathrm{mg}$ of MAPGA was dispersed into two $40 \mathrm{~mL}$ tubes, containing PBS solutions at $\mathrm{pH} 4.8$ and 7.4, which were placed in a shaker. The temperature was set at $37^{\circ} \mathrm{C}$, $3 \mathrm{~mL}$ of the release media was extracted at different time intervals, starting with first $5 \mathrm{~min}$, then $30 \mathrm{~min}$ and subsequently hourly until 12,24 and $48 \mathrm{~h}$ were attained. The absorbance of the solutions withdrawn was obtained with 
Lambda35 UV-Vis spectrophotometer at the $\lambda_{\max }$ of protocatechuic acid $(259 \mathrm{~nm})$.

\section{Cell culture}

Human liver hepatocellular carcinoma cell line (HepG2) and standard fibroblast cell lines (3T3) were acquired from ATCC and were utilized in cancer and cytotoxicity studies, respectively. The cell lines growth was done in an RPMI 1640 with $10 \%$ fetal bovine serum (FBS) and $1 \%$ penicillin/streptomycin. The cells were cultured at $80 \%$ confluence and as adherent monolayers. The culturing conditions were maintained at $37{ }^{\circ} \mathrm{C}$ and $5 \% \mathrm{CO}_{2}$ atmosphere (humidified). Trypsinization was used for culture harvest in a trypsin-EDTA solution. All reagents were used as purchased.

\section{MTT cell viability assays}

For the MTT assay, the same medium and culture conditions was used for cell culture. Subsequently, the grown cells were harvested and counted before being transferred into $1 \times 10^{4}$ cells/well-sized 96-well plates; addition of the free drug, pure LDH and MAPGAu nanocomposite immediately followed. The cells were then incubated for $24 \mathrm{~h}$. The cells were allowed $24 \mathrm{~h}$ attachment in the culture medium prior to the treatment. The MAPGAu nanocomposite, the pure LDH and free drug were then administered in different concentrations and incubated for $72 \mathrm{~h}$. For the MMT, $2 \mathrm{~mL}$ of PBS was used to dissolve $5 \mathrm{mg}$ of 3-[4, 5-dimethylthiazol2-yl]-2, 5-diphenyltetrazolium bromide (MTT); $20 \mu \mathrm{L}$ of the prepared solution was divided into 96 -well plates. The purple-colored formazan product was established after $3 \mathrm{~h}$ of incubation at $37{ }^{\circ} \mathrm{C}$. The unbound MTT as well as dead cells in the media were removed via suction. Consequently, DMSO $(100 \mu \mathrm{L})$ was introduced to each well. The cells were then shaken and microplate reader was used to measure the optical densities of the cells at $570 \mathrm{~nm}$. The analyses were repeated three times each, and the viabilities of the cells and control cells were calculated in percentage.

\section{Magnetic resonance imaging analysis}

The inherent signal intensity for the MAPGAu nanocomposite was tested with a 3.0 T MRI clinical instrument $(3.0 \mathrm{~T}$ Siemens Magnetom). The samples were prepared with reference to $\mathrm{Gd}^{3+}$ content in the MAPGAu. The concentrations were varied from high to low, starting with 2.0 , then 0.5 and 0.2. The references $\mathrm{Gd}\left(\mathrm{NO}_{3}\right)_{3}(0.5(\mathrm{w} / \mathrm{v})$ and water), along with the MAPGAu samples were prepared in tubes and placed on an MRI phantom. The phantom served as the holder for the samples, which was placed in the magnetic source area of the MRI machine. The imaging conditions were set at field of view (FOV) $120 \times 120$ and TR/TE (83/9000) $224 \times 220$ s. Syngovia MRI software was adopted in the extraction and analysis of the recorded data of the T1-weighted images.

Acknowledgements The funds for this research were provided by Universiti Putra Malaysia (UPM) and the Ministry of Higher Education of Malaysia (MOHE) under NanoMITe Grant Vot No. 5526300.

\section{Compliance with ethical standards}

Conflict of interest None of the authors of this manuscript have any competing interests.

Open Access This article is distributed under the terms of the Creative Commons Attribution 4.0 International License (http://creativeco mmons.org/licenses/by/4.0/), which permits unrestricted use, distribution, and reproduction in any medium, provided you give appropriate credit to the original author(s) and the source, provide a link to the Creative Commons license, and indicate if changes were made.

\section{References}

Aisawa S, Sasaki S, Takahashi S, Hirahara H, Nakayama H, Narita E (2006) Intercalation of amino acids and oligopeptides into $\mathrm{Zn}$ Al layered double hydroxide by coprecipitation reaction. J Phys Chem Solids 67(5):920-925

Anter J, Romero-Jiménez M, Fernández-Bedmar Z, Villatoro-Pulido M, Analla M, Alonso-Moraga A, Muñoz-Serrano A (2011) Antigenotoxicity, cytotoxicity, and apoptosis induction by apigenin, bisabolol, and protocatechuic acid. J Med Food 14(3):276-283

Barahuie F, Hussein MZ, Hussein-Al-Ali SH, Arulselvan P, Fakurazi S, Zainal Z (2013) Preparation and controlled-release studies of a protocatechuic acid-magnesium/aluminum-layered double hydroxide nanocomposite. Int J Nanomed 8:1975. https://doi. org/10.2147/ijn.s42718

Barahuie F, Hussein MZ, Arulselvan P, Fakurazi S, Zainal Z (2014) Drug delivery system for an anticancer agent, chlorogenate-Zn/ Al-layered double hydroxide nanohybrid synthesised using direct co-precipitation and ion exchange methods. J Solid State Chem 217:31-41. https://doi.org/10.1016/j.jssc.2014.04.015

Barahuie F, Dorniani D, Saifullah B, Gothai S, Hussein MZ, Pandurangan AK, Norhaizan ME (2017) sustained release of anticancer agent phytic acid from its chitosan-coated magnetic nanoparticles for drug-delivery system. Int J Nanomed 12:2361

Bi Y, Cao X, Liu M, Meng X, Zhai H (2014) A smart drug delivery system in response to time, $\mathrm{pH}$ and enzyme for colorectal cancer therapy and its targeted release performance in vitro. Mater Lett 137:354-357

Bullo S, Hussein MZ (2015) Inorganic nanolayers: structure, preparation, and biomedical applications. Int J Nanomed. https://doi. org/10.2147/ijn.s72330

Bullo Saifullah MZH, Hussein-Al-Ali SH, Arulselvan P, Fakurazi S (2013) Antituberculosis nanodelivery system with controlledrelease properties based on para-amino salicylate-zinc aluminumlayered double-hydroxide nanocomposites. Drug Des Dev 7:1365

Caravan P (2006) Strategies for increasing the sensitivity of gadolinium based MRI contrast agents. Chem Soc Rev. https://doi. org/10.1039/b510982p 
Cavani F, Trifirò F, Vaccari A (1991) Hydrotalcite-type anionic clays: preparation, properties and applications. Catal Today 11(2):173-301

Dorniani D, Hussein MZB, Kura AU, Fakurazi S, Shaari AH, Ahmad Z (2012) Preparation of Fe. Int J Nanomed 7:5745-5756

Dorniani D, Kura AU, Hussein-Al-Ali SH, Bin Hussein MZ, Fakurazi S, Shaari AH, Ahmad Z (2014) In vitro sustained release study of gallic acid coated with magnetite-PEG and magnetite-PVA for drug delivery system. Sci World J 2014, ID 416354. https://doi. org/10.1155/2014/416354

Duc G, Roux S, Paruta-Tuarez A, Dufort S, Brauer E, Marais A, Lux F et al (2014) Advantages of gadolinium based ultrasmall nanoparticles vs molecular gadolinium chelates for radiotherapy guided by MRI for glioma treatment. Cancer Nanotechnol. https://doi. org/10.1186/s12645-014-0001-y

Eisenberg D, Kauzmann W (2005) The structure and properties of water. Oxford University Press, Oxford

King SR, Shimmon S, Gentle AR, Westerhausen MT, Dowd A, McDonagh AM (2016) Remarkable thermal stability of gold nanoparticles functionalised with ruthenium phthalocyanine complexes. Nanotechnology 27(21):215702

Krishnamoorthy K, Navaneethaiyer U, Mohan R, Lee J, Kim S-J (2012) Graphene oxide nanostructures modified multifunctional cotton fabrics. Appl Nanosci 2(2):119-126

Kura AU, Hussein MZ, Fakurazi S, Arulselvan P (2014) Layered double hydroxide nanocomposite for drug delivery systems; biodistribution, toxicity and drug activity enhancement. Chem Cent J. https://doi.org/10.1186/1752-153x-8-1

Liu C-L, Wang J-M, Chu C-Y, Cheng M-T, Tseng T-H (2002) In vivo protective effect of protocatechuic acid on tert-butyl hydroperoxide-induced rat hepatotoxicity. Food Chem Toxicol 40(5):635-641

Liu W, Hsu C, Yin M (2008) In vitro anti-Helicobacter pylori activity of diallyl sulphides and protocatechuic acid. Phytother Res 22(1):53-57

Mirza AZ, Siddiqui FA (2014) Nanomedicine and drug delivery: a mini review. Int Nano Lett 4(1):94

Nakamura Y, Torikai K, Ohto Y, Murakami A, Tanaka T, Ohigashi H (2000) A simple phenolic antioxidant protocatechuic acid enhances tumor promotion and oxidative stress in female ICR mouse skin: dose-and timing-dependent enhancement and involvement of bioactivation by tyrosinase. Carcinogenesis 21(10):1899-1907

National Institute for Public Health and the Environment, Ministry of Health, Welfare and Support (2012) Interpretation and implications of the European Commission recommendation on the definition of nanomaterial. RIVM letter report. Accessed Dec 2017

Nityashree N, Menezes P (2013) Mg/Al layered double hydroxidePt nanoparticle composite by delamination-restacking route. Appl Nanosci 3(4):321-327. https://doi.org/10.1007/s1320 4-012-0137-1

Raffi M, Mehrwan S, Bhatti TM, Akhter JI, Hameed A, Yawar W, ul Hasan MM (2010) Investigations into the antibacterial behavior of copper nanoparticles against Escherichia coli. Ann Microbiol 60(1):75-80. https://doi.org/10.1007/s13213-010-0015-6

RxList (2016) Drug index. http://www.rxlist.com. Accessed 15 Dec 2017

Saifullah B, Hussein MZ, Hussein-Al-Ali SH, Arulselvan P, Fakurazi S (2013) Sustained release formulation of an anti-tuberculosis drug based on para-amino salicylic acid-zinc layered hydroxide nanocomposite. Chem Cent J 7(1):72. https://doi. org/10.1186/1752-153x-7-72
Sheng Z, Hu D, Xue M, He M, Gong P, Cai L (2013) Indocyanine green nanoparticles for theranostic applications. Nano Micro Lett 5(3):145-150

Stagos D, Kazantzoglou G, Theofanidou D, Kakalopoulou G, Magiatis P, Mitaku S, Kouretas D (2006) Activity of grape extracts from Greek varieties of Vitis vinifera against mutagenicity induced by bleomycin and hydrogen peroxide in Salmonella typhimurium strain TA102. Mutat Res Genet Toxicol Environ Mutagen 609(2):165-175

Sun Z, Jin L, Shi W, Wei M, Duan X (2010) Preparation of an anion dye intercalated into layered double hydroxides and its controllable luminescence properties. Chem Eng J 161(1):293-300

Tan JM, Karthivashan G, Arulselvan P, Fakurazi S, Hussein MZ (2014) Characterization and in vitro studies of the anticancer effect of oxidized carbon nanotubes functionalized with betulinic acid. Drug Des Devel Ther 8:2333

Tang J, Sheng Y, Hu H, Shen Y (2013) Macromolecular MRI contrast agents: structures, properties and applications. Prog Polym Sci. https://doi.org/10.1016/j.progpolymsci.2012.07.001

Thomsen HS (2006) Nephrogenic systemic fibrosis: a serious late adverse reaction to gadodiamide. Springer, Berlin

Uppal MA, Kafizas A, Ewing MB, Parkin IP (2013) The room temperature formation of gold nanoparticles from the reaction of cyclohexanone and auric acid; a transition from dendritic particles to compact shapes and nanoplates. J Mater Chem A 1(25):7351-7359

Usman MS, Ibrahim NA, Shameli K, Zainuddin N, Yunus WMZW (2012) Copper nanoparticles mediated by chitosan: synthesis and characterization via chemical methods. Molecules 17(12):14928-14936

Usman MS, Zowalaty MEE, Shameli K, Zainuddin N, Salama M, Ibrahim NA (2013) Synthesis, characterization, and antimicrobial properties of copper nanoparticles. Int J Nanomed 8:4467-4479

Usman MS, Hussein MZ, Fakurazi S, Ahmad Saad FF (2017a) Gadolinium-based layered double hydroxide and graphene oxide nanocarriers for magnetic resonance imaging and drug delivery. Chem Cent J 11(1):47. https://doi.org/10.1186/s13065-017-0275-3

Usman MS, Hussein MZ, Fakurazi S, Masarudin MJ, Ahmad Saad FF (2017b) Gadolinium-doped gallic acid-zinc/aluminium-layered double hydroxide/gold theranostic nanoparticles for a bimodal magnetic resonance imaging and drug delivery system. Nanomaterials 7(9): 244

Wang L, Xing H, Zhang S, Ren Q, Pan L, Zhang K, Peng W (2013) A Gd-doped $\mathrm{Mg}-\mathrm{Al}-\mathrm{LDH} / \mathrm{Au}$ nanocomposite for CT/MR bimodal imagings and simultaneous drug delivery. Biomaterials 34(13):3390-3401

WHO Cancer (2017) http://www.who.int/cancer/en/. Accessed 15 Dec 2017

Xu W, Kattel K, Park JY, Chang Y, Kim TJ, Lee GH (2012) Paramagnetic nanoparticle T1 and T2 MRI contrast agents. Phys Chem Chem Phys 14(37):12687-12700

Yin M-C, Lin C-C, Wu H-C, Tsao S-M, Hsu C-K (2009) Apoptotic effects of protocatechuic acid in human breast, lung, liver, cervix, and prostate cancer cells: potential mechanisms of action. J Agric Food Chem 57(14):6468-6473

Yuan J, Zhou X, Cao W, Bi L, Zhang Y, Yang Q, Wang S (2017) Improved antitumor efficacy and pharmacokinetics of bufalin via PEGylated liposomes. Nanoscale Res Lett 12(1):585

Publisher's Note SpringerNature remains neutral with regard to jurisdictional claims in published maps and institutional affiliations. 